\title{
Alternative provision of public health care: the role of citizens' satisfaction with public services and the social responsibility of government - ERRATUM
}

\author{
N. Cohen, S. Mizrahi and E. Vigoda-Gadot
}

(First published online 24 August 2020)

https://doi.org/10.1017/S1744133120000201, Published by Cambridge University Press, 20 July 2020.

Key words: Alternative provision; citizens' satisfaction; informal payments; social responsibility

When originally published, the article by Cohen et al, included incomplete citations which are updated as described below.

On Page 2, line 28 the missing citation should have been (Cohen, 2012) and the full reference is:

Cohen, Nissim (2012) "Informal Payments for Healthcare - The Phenomenon and its Context" Health Economics, Policy \& Law, 7 (3): 285-308.

On Page 2, line 43 the missing citation should have been (Cohen and Flic, 2017) and the full reference is:

Cohen, Nissim \& Filc, Dani (2017). “An alternative way of understanding exit, voice and loyalty: the case of informal payments for health care in Israel" The International Journal of Health Planning and Management, 32 (1): 72-90.

On Page 3, line 1 the missing citation should have been (Filc and Cohen, 2015) and the full reference is:

Filc, Dani \& Cohen, Nissim (2015) "Blurring the Boundaries between Public and Private Health Care Services as an Alternative Explanation for the Emergence Black Medicine: The Israeli Case” Health Economics, Policy \& Law, 10 (3): 293-310.

\section{Reference}

Cohen, N, et al. (2020) Alternative provision of public health care: the role of citizens' satisfaction with public services and the social responsibility of government. Health Economics, Policy and Law. https://doi.org/10.1017/S1744133120000201

\footnotetext{
Cite this article: Cohen N, Mizrahi S, Vigoda-Gadot E (2022). Alternative provision of public health care: the role of citizens' satisfaction with public services and the social responsibility of government - ERRATUM. Health Economics, Policy and Law 17, 120-120. https://doi.org/10.1017/S1744133120000298

(c) The Author(s), 2020. Published by Cambridge University Press. This is an Open Access article, distributed under the terms of the Creative Commons Attribution licence (http://creativecommons.org/licenses/by/4.0/), which permits unrestricted re-use, distribution, and reproduction in any medium, provided the original work is properly cited.
} 